\title{
New Biomarkers of Chronic Hepatitis B
}

\author{
Lung-Yi Mak ${ }^{1}$, Wai-Kay Seto ${ }^{1,2,3}$, James Fung ${ }^{1,2}$, and Man-Fung Yuen ${ }^{1,2}$ \\ ${ }^{1}$ Department of Medicine, Queen Mary Hospital, The University of Hong Kong, ${ }^{2}$ State Key Laboratory for Liver Research, The University of \\ Hong Kong, Hong Kong, and ${ }^{3}$ Department of Medicine, The University of Hong Kong-Shenzhen Hospital, Shenzhen, China
}

Chronic hepatitis B $(\mathrm{CHB})$ infection leads to clinically heterogeneous disease outcomes. Different viral markers are utilized to monitor treatment effects and predict risk of complications in patients with $\mathrm{CHB}$. Hepatitis B core-related antigen (HBcrAg) is a novel serum composite viral protein whose performance has been proven to be superior to that of existing viral markers. It showed good correlation with intrahepatic covalently closed-circular DNA. Its profile differs drastically in patients in different disease phases, and the level declines with antiviral therapies. HBcrAg may be helpful for predicting hepatocellular carcinoma development and hepatitis $B$ virus (HBV) reactivation in immunosuppressed patients. Another emerging measurable serum marker, HBV RNA, exists in the form of pregenomic RNA-containing virions. Its profile differs between patients in different disease phases in a similar manner to that of HBcrAg. HBV RNA is present in serum at lower levels than HBV DNA in treatment-naiive patients by 1-2 logs. In contrast, its level is higher than HBV DNA in patients receiving nucleos(t)ide analogues (NAs). A significant decline in serum RNA was observed in patients receiving novel antiviral therapies, including core protein allosteric modulators and RIG-1/NOD2 agonists. Both HBcrAg and HBV RNA may be helpful for predicting off-therapy sustained virological control in patients who stop long-term NA treatment. (Gut Liver 2019;13:589-595)

Key Words: Hepatitis B core-related antigen; Hepatitis B virus RNA; Biomarkers

\section{INTRODUCTION}

Hepatitis B virus (HBV) is the only hepatotropic virus which exists in DNA form. It infects human livers and exerts necroinflammatory, fibrotic and carcinogenic effects. ${ }^{1}$ Most patients with chronic HBV (CHB) infection acquire the virus via vertical/ early-age horizontal transmission. Up to $15 \%-40 \%$ of them will progress to cirrhosis, decompensated liver disease, hepatocellular carcinoma (HCC) or death, and liver transplantation may be required in patients with advanced liver disease. ${ }^{2}$ Current available antiviral therapies including pegylated interferon (PEG-IFN) and nucleos(t)ide analogues (NA) ${ }^{3}$ are effective in controlling or suppressing viral replication. However, a complete cure, as defined by the total eradication of the virus from the liver, is not achieved due to the persistence of covalently closed circular DNA (cccDNA). ${ }^{4,5}$ The surrogate treatment endpoint of HBV surface antigen (HBsAg) seroclearance, known as a functional cure, is deemed more feasible, and has been shown to be associated with significantly lower risk of liver-related complications, ${ }^{6}$ despite being only achieved in a minority of patients. ${ }^{7-9}$ Ongoing efforts are made to develop novel anti-HBV drugs to act against various steps of the HBV replication cycle, aiming to enhance virological control and promote functional cure. ${ }^{10}$ For the majority of patients with $\mathrm{CHB}$ who do not achieve functional cure, long term NA is likely needed. In spite of this long-term therapy, liver-related complications can still occur even with sustained viral suppression. To this end, newer virological markers have been developed to predict the risk of liver-related complications in these patients who often have undetectable serum HBV DNA, and the likelihood of achieving functional cure or partial cure, which is defined as off-therapy virological suppression. In the following sections, two novel serum biomarkers developed for these purposes will be discussed: HBV core-related antigen (HBcrAg) and HBV RNA.

\section{HEPATITIS B CORE-RELATED ANTIGEN}

\section{Overview}

Following viral entry into the hepatocyte, the relaxed circular DNA (rcDNA) is converted into cccDNA minichromosome, which is used as a template for subsequent transcription and

\section{Correspondence to: Man-Fung Yuen}

Department of Medicine, Queen Mary Hospital, The University of Hong Kong, Pokfulam Road 102, Hong Kong

Tel: +852-22553994, Fax: +852-28162863, E-mail: mfyuen@hkucc.hku.hk

Received on September 20, 2018. Accepted on November 12, 2018. Published online March 5, 2019.

pISSN 1976-2283 eISSN 2005-1212 https://doi.org/10.5009/gnl18425

@ This is an Open Access article distributed under the terms of the Creative Commons Attribution Non-Commercial License (http://creativecommons.org/licenses/by-nc/4.0) which permits unrestricted non-commercial use, distribution, and reproduction in any medium, provided the original work is properly cited. 
translation into viral proteins. Among the many viral proteins synthesized, three related viral proteins, sharing an identical 149 amino acid sequence, make up the HBcrAg. These include the $\mathrm{HBV}$ core antigen ( $\mathrm{HBcAg})$-structural component of the viral capsid, HBV e antigen ( $\mathrm{HBeAg}$ )-the $\mathrm{N}$-terminal processed product of the precore protein, and a truncated $22 \mathrm{kDa}$ precore protein (p22Cr)-also processed product of precore protein with additional protein processing at both the $\mathrm{N}$ - and C-terminals (Fig. 1). ${ }^{11,12}$ Serum HBcrAg can be detected and quantified with the chemiluminescence method. ${ }^{11}$ In the following sections, the clinical relevance of $\mathrm{HBcrAg}$ will be discussed.

\section{Profile in natural history of $\mathrm{CHB}$}

The profile of serum HBcrAg in different disease phases of $\mathrm{CHB}$ has been characterized by two studies involving Asian and European patients with genotype A-D HBV infection. ${ }^{13,14}$ In both studies, the serum HBcrAg level was significantly higher in $\mathrm{HBeAg}$-positive patients compared to HBeAg-negative patients, owing to the fact that $\mathrm{HBeAg}$ production (one of the components of $\mathrm{HBcrAg}$ ) was diminished after HBeAg seroconversion. More importantly, serum HBcrAg may be able to differentiate between chronic infection and chronic hepatitis. For HBeAgpositive patients, chronic infection was associated with higher HBcrAg than chronic hepatitis (8.54 and $7.92 \log \mathrm{U} / \mathrm{mL}$, respectively, $\mathrm{p}<0.001$ ). For HBeAg-negative patients, chronic infection was associated with lower HBcrAg than chronic hepatitis (2.60 and $4.92 \log \mathrm{U} / \mathrm{mL}$, respectively, $\mathrm{p}<0.001) .{ }^{14}$ For HBsAgnegative patients, that is, those achieved functional cure, serum HBcrAg was only detected in $21 \%$ with a median level of 2.7 $\log \mathrm{U} / \mathrm{mL} .^{14,15}$

Serum HBcrAg correlated well with serum HBV DNA (r, 0.69 to $0.87 ; \mathrm{p}<0.001),{ }^{16-19}$ serum HBsAg titre $(\mathrm{r}=0.703, \mathrm{p}<0.001),{ }^{14}$ intrahepatic total DNA (r, 0.664 to $0.70 ; \mathrm{p}<0.001)^{18,19}$ and intrahepatic cccDNA $(r=0.664, \mathrm{p}<0.001)$ (Table 1$).^{18}$

\section{Profile in patients undergoing antiviral treatment}

Although NAs are potent inhibitors of viral replication with marked HBV DNA suppression, the ongoing inhibitory effects of NA on intrahepatic viral reservoir, as reflected by progressive decline of other viral markers, is more modest. In a study of 222 patients on entecavir (ETV) for 7 years, serum HBcrAg declined at a rate of $0.244 \log \mathrm{kU} / \mathrm{mL} / \mathrm{year}$, which was more impressive than the decline in serum HBsAg titre of $0.107 \log \mathrm{IU} / \mathrm{mL} / \mathrm{year}^{20}$ Almost one-third (32\%) even achieved undetectable serum HBcrAg at year $7 .^{20}$ Serum HBcrAg showed persisted linear correlation with intrahepatic cccDNA, even in treatment-experienced patients $(\mathrm{r}=0.692, \mathrm{p}<0.001){ }^{21}$ The decline in serum HBcrAg observed in patients on long term NA therapy correlated modestly with decline in the intrahepatic cccDNA ( $\mathrm{r}=0.419, \mathrm{p}=0.005){ }^{22}$

Less data exists for the kinetics of HBcrAg in patients treated with PEG-IFN. One study $(n=58)$ reported significant decline of serum HBcrAg from $8.042 \log \mathrm{U} / \mathrm{mL}$ at baseline to $5.301 \log \mathrm{U} /$ $\mathrm{mL}$ at 24 weeks after completion of a 48 -week course of PEGIFN. ${ }^{23}$ Due to the small number of patients and short follow-up duration, the effects of a finite duration PEG-IFN on the profile of serum $\mathrm{HBcrAg}$ in the long term remains elusive.

The kinetics of HBcrAg using novel anti-HBV compounds has been described. ARC-520 is a RNA interference agent which directly targets cccDNA-derived transcription and blocks downstream viral replicatory steps. After a single dose of intravenous ARC-520, serum HBcrAg reduced by $1.4 \log \mathrm{kU} / \mathrm{mL}$ at 85 days of dosing. ${ }^{24}$ ARC-520 initially entered phase 2 clinical trial, but

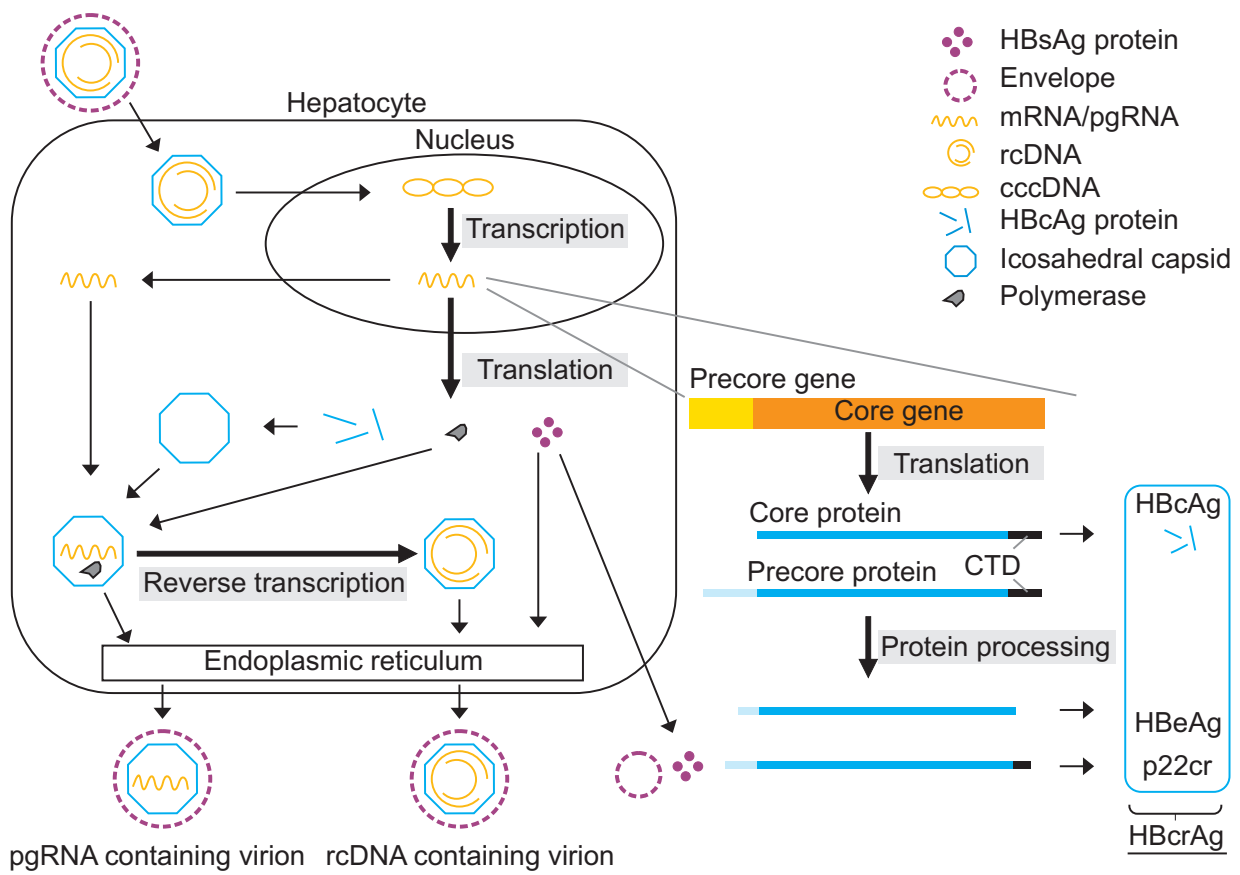

Fig. 1. Schematic illustration of the hepatitis B virus (HBV) replication cycle and production of viral markers. HBsAg, HBV surface antigen; mRNA, messenger RNA; pgRNA, pregenomic RNA; rcRNA, relaxed circular DNA; cccDNA, covalently closed circular DNA; HBcAg, HBV core antigen; CTD, C-terminal domain; HBeAg, HBV e antigen; p22cr, truncated $22 \mathrm{kDa}$ precore protein; HBcrAg, hepatitis B core-related antigen. 
Table 1. Correlation between Serum HBcrAg and HBV RNA with Respect to Intrahepatic cccDNA

\begin{tabular}{lcccc}
\hline & \multicolumn{2}{c}{ Treatment naïve } & \multicolumn{2}{c}{ Treatment experienced } \\
\cline { 2 - 5 } \cline { 3 - 4 } HBcrAg & r & p-value & r & p-value \\
\hline HBV RNA & $0.664-0.70$ & $<0.001^{18,19}$ & 0.692 & $<.001^{21}$ \\
& HBeAg-positive: 0.39 & $0.002^{45}$ & 0.08 & $0.55^{44}$ \\
& HBeAg-negative: 0.1 & $0.654^{45}$ & & \\
\hline
\end{tabular}

HBcrAg, hepatitis B core-related antigen; HBV, hepatitis B virus; cccDNA, covalently closed circular DNA; HBeAg, hepatitis B e antigen.

was subsequently discontinued due to deaths observed in nonhuman primates receiving excessive doses. Nevertheless, other RNA interference compounds are being actively developed, and the findings from the ARC-520 study showed that serum HBcrAg may be a suitable marker for monitoring of the treatment effects.

\section{Potential clinical applications}

Previous studies have demonstrated a potential role for HBcrAg in determining risk for HCC development. Higher serum HBcrAg was shown to be associated with HCC development in both treatment-naïve and treatment-experienced patients. In 1,031 treatment-naïve patients where 78 developed HCC at a median of 10.7 years, serum $\mathrm{HBcrAg}>2.9 \log \mathrm{U} / \mathrm{mL}$ was associated with 5-fold increased risk of HCC. ${ }^{25}$ In 76 patients treated with NA who had undetectable serum HBV DNA, posttreatment serum $\mathrm{HBcrAg}$ of $>3.89 \log \mathrm{U} / \mathrm{mL}$ was associated with 3-fold increased risk of $\mathrm{HCC}^{26}$

The risk of HBV reactivation after immunosuppressive therapy may also be predicted by serum HBcrAg in patients with occult hepatitis B infection. In $124 \mathrm{HBsAg}-/$ anti-HBc+ patients with undetectable serum HBV DNA who received rituximab or underwent allogeneic hematopoietic stem cell transplantation, cumulative rate of $\mathrm{HBV}$ reactivation was $40.4 \%$ at 2-year. Serum HBcrAg at baseline was detectable in 43 patients (34.7\%) and was associated with almost 3-fold increased risk of HBV reactivation compared to patients without detectable serum $\mathrm{HB}$ crAg. ${ }^{27}$

Levels of HBcrAg may also potentially predict the likelihood of achieving partial cure in patients on antiviral therapy, as defined by a sustained off-therapy virological control. These patients may be able to discontinue NA with close monitoring for virological breakthroughs. Different markers, including $\mathrm{HBsAg}$ titre, have been reported to show predictive ability for post-NA cessation virological relapse. ${ }^{28}$ The role of serum HBcrAg in this special population was also investigated in $45 \mathrm{HBeAg}$-negative patients, showing that a high end-of-therapy serum HBcrAg $>3.7 \log \mathrm{IU} / \mathrm{mL}$ was associated with 3.7-fold risk of virological relapse within one year of NA cessation. ${ }^{29}$

From the above studies, it is clear that serum HBcrAg levels would carry multiple implications depending on the context of measurement. Extra care should be taken when interpreting the results, taking into account the HBsAg status, the phase of disease, the duration of antiviral treatment and the indication of measurement. $^{30}$

\section{HEPATITIS B VIRUS RNA}

\section{Overview}

Earlier concepts regarding HBV replication did not acknowledge the presence of HBV RNA outside hepatocytes, as completion of rcDNA synthesis, the so-called "mature genome," was considered to be necessary for envelopment and exit of virions to the blood stream. ${ }^{31,32}$ In recent studies, HBV RNA have been shown to be detectable in serum of patients who are either treatment-naïve or treatment-experienced, challenging the concept that only rcDNA-containing virions can be secreted. Indeed, the serum HBV RNA is present in the form of virion containing primarily full-length pregenomic RNA (pgRNA), which is encapsidated by $\mathrm{HBc}$ protein, rather than preC mRNA that bears the same length of $3.5 \mathrm{~kb}$, nor is it associated with exosomes (Fig. 1). ${ }^{33}$ Most studies measure serum HBV RNA using standardized multistep procedures. In simple terms, these include serum HBV nucleic acid extraction, DNA digestion, reverse transcription of RNA (targeting specific HBV gene regions) to complementary DNA, followed by real-time polymerase chain reaction. ${ }^{34-41}$ In the following sections, the clinical relevance of circulating HBV RNA will be discussed.

\section{Profile in natural history of $\mathrm{CHB}$}

In general, HBV RNA is present in treatment naïve CHB patients in lower levels compared to HBV DNA by approximately $1-2 \log _{10}$ copies $/ \mathrm{mL}^{42}$ In a study of 11 patients, serum HBV DNA and HBV RNA were 7.87 and $6.31 \log _{10}$ copies $/ \mathrm{mL}$, respectively $(p=0.007) .^{33}$ In another study characterizing HBV RNA in the natural history of CHB in a larger population of 102 untreated patients, serum HBV RNA was found to differ significantly between the disease phases, a phenomenon similar to HBcrAg. The highest levels were observed in HBeAg-positive chronic infection, followed by HBeAg-positive chronic hepatitis, HBeAg-negative chronic hepatitis, and lowest in HBeAg-negative chronic infection $\left(6.78,5.73,4.52\right.$, and $2.96 \log _{10}$ copies/ $\mathrm{mL}$, respectively; $\mathrm{p}<0.001$ for inter-group comparisons and for trend). ${ }^{43}$ 
Serum HBV RNA demonstrated different degrees of correlation with known viral markers in treatment naïve patients. Regarding serum HBV DNA, there was strong linear correlation between these two viral nucleic acids $(r=0.928, p<0.001) .{ }^{43}$ Serum HBV RNA level also showed good linear correlation with serum HBsAg titre $(\mathrm{r}=0.67, \mathrm{p}<0.001){ }^{44}$ In comparison, serum HBV RNA showed only modest linear correlations with intrahepatic cccDNA in HBeAg-positive patients $\left(r=0.39, p=0.002^{45}\right.$ or $\mathrm{r}=0.25, \mathrm{p}=0.02^{44}$ ) and no significant correlation in HBeAgnegative patients $(\mathrm{r}=0.10 \mathrm{p}=0.654)$ (Table 1$){ }^{45}$

\section{Profile in patients undergoing approved antiviral treat- ment}

In contrast to untreated patients, a relatively higher serum HBV RNA level with respect to HBV DNA level was observed in patients treated with NAs. ${ }^{42}$ This can be explained by the fact that HBV pgRNA is only produced from cccDNA by transcription. Any secreted pgRNA-containing virions originate from partially or un-transcribed pgRNA, which is paradoxically increased when reverse transcriptase and DNA polymerase activities are inhibited by NA. ${ }^{33}$ Therefore, it is not surprising that serum HBV RNA could still be detected even in patients who had undetectable serum HBV DNA after NA treatment. In a cross-sectional study involving 47 patients treated with ETV for a median duration of 3 years with undetectable serum HBV DNA, serum HBV RNA was still detected in 35 (74.47\%) at a median level of 3.02 (range, 2.33 to 4.80 ) $\log _{10}$ copies $/ \mathrm{mL}$. There was significant correlation between serum HBV RNA and serum HBsAg titre $(\mathrm{r}=0.665, \mathrm{p}<0.001)$, intrahepatic HBV RNA level $(\mathrm{r}=0.725, \mathrm{p}<0.001)$ as well as histological disease severity in terms of grading of necro-inflammation $(r=0.665, p<0.001)$ and staging. However, intrahepatic cccDNA showed no correlation with serum HBV RNA after antiviral therapy (Table 1). ${ }^{44}$

Serum HBV RNA might also be useful in predicting treatment response in patients receiving NA monotherapy, and in NA-induced HBeAg seroconversion. A low on-treatment serum HBV RNA at week 12 of lamivudine or ETV was associated with shorter interval to achieve serum HBV DNA undetectability $(\mathrm{n}=52){ }^{40}$ Among $50 \mathrm{HBeAg}$-positive patients who received NA for a mean duration of 19 months, 15 patients who achieved HBeAg seroconversion had significantly greater decline in serum HBV full-length RNA from baseline by $1 \log _{10}$ and $1.8 \log _{10}$ at 3 months and 6 months, respectively $(p<0.001$ for months 3 and 6), compared to 35 patients without HBeAg seroconversion. ${ }^{39}$

The profile of serum HBV RNA in patients receiving combination PEG-IFN and NA therapy was also reported. Similar to NA monotherapy, serum HBV RNA was relatively higher compared to serum HBV DNA. This was demonstrated in a study of 23 patients (13 $\mathrm{HBeAg}$-positive and $10 \mathrm{HBeAg}$-negative) who were treated with 48 weeks combination PEG-IFN alfa-2a with adefovir. Moreover, the decline in HBV RNA levels in HBeAg- positive patients was greater for those on combination therapy from 30 weeks onwards compared to patients on NA monotherapy. In both HBeAg-positive and HBeAg-negative patients, responders to combination therapy had significantly lower serum HBV RNA levels compared to non-responders from 30 weeks onwards, and baseline HBV RNA was independently associated with treatment response (odds ratio $=0.44, p=0.019$ ). ${ }^{35}$

\section{Profile in patients undergoing novel anti-HBV drug trials}

Owing to the different mechanisms of action against HBV in novel therapies, traditional viral markers may not be sufficient to reflect the mechanistic effects of these novel agents. Novel markers including serum HBV RNA therefore emerge as an important marker to monitor their antiviral effects. The profile of serum HBV RNA has been characterized in two classes of novel agents: core protein allosteric modulators (CpAM) and retinoic acid-inducible gene I/nucleotide-binding oligomerization domain-containing protein 2 (RIG-I/NOD2) agonist.

For CpAM, serum HBV RNA was measured in 73 HBeAg-positive treatment-naïve patients who were treated with NVR3-778, PEG-IFN or NVR3-778 + PEG-IFN. After 28 days of therapy, all patients treated with $600 \mathrm{mg}$ BD or 1,000 mg BD NVR3-778 monotherapy had serum HBV RNA decline by $>0.5 \log _{10} \mathrm{IU} / \mathrm{mL}$, and all patients treated with combination NVR3-778 + PEG-IFN had serum HBV RNA decline by $>1.0 \log _{10}$ copies $/ \mathrm{mL}$. The biggest drop of HBV RNA from baseline was observed in patients treated with combination NVR3-778 + PEG-IFN (-2.06 $\log _{10}$ copies/mL for cohort taking $600 \mathrm{mg}$ BD NVR3-778), followed by NVR3-778 monotherapy $\left(-1.42 \log _{10}\right.$ copies/mL), and PEGIFN monotherapy $\left(-0.89 \log _{10}\right.$ copies/mL). There was high linear correlation between serum HBV RNA and DNA levels ( $\mathrm{r}=0.91$, $\mathrm{p}<0.0001) .{ }^{46}$ The decline in HBV RNA with BVR3-778 is not surprising. CpAM inhibits the formation of normal icosahedral capsids, which is responsible for the encapsidation of pgRNA, a prerequisite for subsequent excretion into the circulation as RNA-containing virions.

For RIG-I/NOD2 agonist, serum HBV RNA was measured in 20 patients who were treated with SB 9200 (Inarigivir soproxil) for 12 weeks at different doses followed by 12 weeks of TDF. At week 12 of therapy, compared to placebo, significant decline in serum HBV RNA from baseline was observed only in 11 HBeAg-negative patients but not in the nine HBeAg-positive patients. In addition, the serum HBV RNA decline observed in HBeAg-negative patients was dose-dependent: $-1.84 \log _{10}$ and -3.15 $\log _{10}$ for SB 9200 (25 mg) and SB 9200 (50 mg), respectively. Of the $11 \mathrm{HBeAg}$-negative patients, nine had undetectable serum HBV RNA at week 24. In contrast, only two out of the nine $\mathrm{HBeAg}$-positive patients had undetectable serum $\mathrm{HBV}$ RNA at the same time point. ${ }^{47}$ RIG-I and NOD2 are host pattern recognition receptors which are viral sensor proteins that induces interferon-mediated antiviral immune responses in virusinfected cells. In addition, RIG-1 binding to pgRNA suppresses 
its encapsidation, leading to a reduction in RNA-containing virion secretion. $^{48}$

Since novel anti-HBV agents act on different steps from NAs in the viral replication cycle, serum HBV DNA is no longer sufficient to assess treatment response for these newer compounds. From the above examples, serum HBV RNA might act as an additional useful marker for monitoring the direct antiviral effects of these novel therapies.

\section{Potential clinical applications}

The need to identify patients with high risk of post-NA cessation relapse has been discussed above. Apart from serum HBcrAg, serum HBV RNA has also been shown to predict virological relapse after NA cessation. In a study of 36 patients who stopped NA after a mean treatment duration of 36 weeks, 19 $(52.8 \%)$ developed post-NA cessation viral rebound at 24 weeks after treatment discontinuation. On-therapy HBV DNA + RNA titres decreased rapidly in the non-rebound group compared to that in the rebound group. More specifically, on-therapy high serum HBV DNA + HBV RNA titres at 3 months was significantly associated with viral rebound (odds ratio $=9.474$, $\mathrm{p}=0.043){ }^{41}$ In another study of 33 patients who had taken $>3$ years of NA with undetectable serum HBV DNA, 21 still had detectable serum HBV RNA at the time of treatment cessation. At 24 weeks after NA cessation, viral rebound occurred in all 21 patients (100\%), compared to only three (25\%) of the 12 patients with undetectable serum HBV RNA $(p=0.001){ }^{33}$ The presence of pgRNA virion in the serum may reflect the ongoing transcriptional activity of cccDNA and signifies lower chance of sustained off-therapy virological suppression.

Serum RNA has also been studied in patients after acute HBV infection. Currently, no accurate marker exists to predict the persistence of HBV after acute infection. It often relies on clinical history and repeated serological monitoring of HBsAg and HBV DNA. Serum HBV RNA was characterized in three blood donor samples with positive IgM anti-HBc (consistent with acute HBV infection). Serum pgRNA was detectable throughout the viraemic phase, being 2.33 to 2.58 log lower than serum HBV DNA in two patients who had resolved HBV infection, compared to $1.85 \log$ lower than serum HBV DNA in the remaining patient who had persistent HBsAg seropositivity for $>6$ months. However, no significant differences could be observed in terms of correlations of RNA and DNA between the two patients who had resolved HBV infection compared to the patient who evolved into chronic HBV carrier. ${ }^{42}$ The role of serum HBV RNA in prediction of HBV chronicity after acute exposure remains to be determined.

\section{CONCLUSION AND FUTURE DIRECTIONS}

Both serum HBcrAg and HBV RNA are emerging markers for diagnosis, monitoring and prognostication in patients with CHB. Table 2 summarizes the potential clinical applications of HBcrAg and HBV RNA in CHB infection. To date, serum HBcrAg has been shown to be the best surrogate marker for intrahepatic cccDNA. It is increasingly studied as a potential

Table 2. Potential Clinical Application of HBcrAg and HBV RNA in Chronic Hepatitis B Infection

\begin{tabular}{|c|c|c|}
\hline Area of interest & HBcrAg & HBV RNA \\
\hline \multicolumn{3}{|l|}{ Natural history } \\
\hline Differentiate disease phases & + & + \\
\hline Predicts spontaneous HBeAg seroconversion & + & No data \\
\hline Predicts spontaneous HBsAg seroclearance & $(-)^{*}$ & No data \\
\hline \multicolumn{3}{|l|}{ Antiviral treatment: PEG-IFN or NA } \\
\hline Predict treatment-induced HBeAg seroconversion & + & + \\
\hline Predict post-NA cessation flare & + & + \\
\hline \multicolumn{3}{|l|}{ Clinical trials of new antiviral agents } \\
\hline Dynamic change in siRNA & + & No data \\
\hline Dynamic change in CpAM & No data & + \\
\hline Dynamic change in RIG-I + NOD2 agonist & No data & + \\
\hline \multicolumn{3}{|l|}{ Special populations } \\
\hline Predict HCC development & + & No data \\
\hline Predict reactivation of HBV under immunosuppression & + & No data \\
\hline Profile in acute infection & No data & $(-)^{\dagger}$ \\
\hline
\end{tabular}

HBcrAg, hepatitis B core-related antigen; HBV, hepatitis B virus; HBeAg, hepatitis B virus e antigen; HBsAg, hepatitis B virus surface antigen; PEG-IFN, pegylated interferon; NA, nucleos(t)ide analogues; siRNA, short interfering RNA; CpAM, core protein allosteric modulators; RIG-I, retinoic acid-inducible gene I; NOD2, nucleotide-binding oligomerization domain-containing protein 2; HCC, hepatocellular carcinoma. ${ }^{*}$ Profile of HBcrAg reported in patients with HBsAg seroclearance, but no further data on predictive power; ${ }^{\dagger}$ Only data on 2 patients with acute HBV infection was reported (see text). 
predictor for HCC development, post-NA cessation relapse, and $\mathrm{HBV}$ reactivation in patients undergoing immunosuppressive therapy. More validation studies are needed to identify specific cutoff values for each clinical outcome. Serum HBV RNA exists as pgRNA-containing virions and reflects upstream viral replication activities. The most relevant application of serum HBV RNA appears to be as a monitoring tool for treatment effect in patients receiving novel anti-HBV therapies. Meanwhile, the specific methods and technical details of serum RNA detection vary widely between different studies and standardization of such is urgently needed. Moreover, whether serum HBV RNA has a role in patients with occult hepatitis B infection, as well as in prediction of HBsAg seroclearance, HCC development and $\mathrm{HBV}$ reactivation in immunosuppressed patients remains to be illustrated by future studies.

\section{CONFLICTS OF INTEREST}

W.K.S. is an advisory board member of Gilead Sciences and Bristol-Myers Squibb and received speaker fees from Gilead Sciences, Bristol-Myers Squibb and Novartis. J. F. received research funding from Novartis. M.F.Y. received speaker fees from GlaxoSmithKline, Bristol-Myers Squibb, Novartis and Gilead Sciences; and received research funding and is an advisory board member of Bristol-Myers Squibb, Novartis and Gilead Sciences. However, all of these are not relevant to this article.

\section{REFERENCES}

1. Yuen MF, Chen DS, Dusheiko GM, et al. Hepatitis B virus infection. Nat Rev Dis Primers 2018;4:18035.

2. Lai CL, Yuen MF. The natural history and treatment of chronic hepatitis B: a critical evaluation of standard treatment criteria and end points. Ann Intern Med 2007;147:58-61.

3. European Association for the Study of the Liver. EASL 2017 Clinical Practice Guidelines on the management of hepatitis B virus infection. J Hepatol 2017;67:370-398.

4. Zoulim F. New insight on hepatitis B virus persistence from the study of intrahepatic viral cccDNA. J Hepatol 2005;42:302-308.

5. Mason AL, Xu L, Guo L, Kuhns M, Perrillo RP. Molecular basis for persistent hepatitis B virus infection in the liver after clearance of serum hepatitis B surface antigen. Hepatology 1998;27:17361742.

6. Yuen MF, Wong DK, Fung J, et al. HBsAg seroclearance in chronic hepatitis B in Asian patients: replicative level and risk of hepatocellular carcinoma. Gastroenterology 2008;135:1192-1199.

7. Fung J, Cheung KS, Wong DK, et al. Long-term outcomes and predictive scores for hepatocellular carcinoma and hepatitis B surface antigen seroclearance after hepatitis B e-antigen seroclearance. Hepatology 2018;68:462-472.

8. Kim GA, Lim YS, An J, et al. HBsAg seroclearance after nucleoside analogue therapy in patients with chronic hepatitis B: clinical outcomes and durability. Gut 2014;63:1325-1332.

9. Liu J, Yang HI, Lee MH, et al. Incidence and determinants of spontaneous hepatitis B surface antigen seroclearance: a communitybased follow-up study. Gastroenterology 2010;139:474-482.

10. Durantel D, Zoulim F. New antiviral targets for innovative treatment concepts for hepatitis B virus and hepatitis delta virus. J Hepatol 2016;64:S117-S131.

11. Kimura T, Ohno N, Terada N, et al. Hepatitis B virus DNA-negative dane particles lack core protein but contain a $22-\mathrm{kDa}$ precore protein without C-terminal arginine-rich domain. J Biol Chem 2005;280:21713-21719.

12. Kimura T, Rokuhara A, Sakamoto Y, et al. Sensitive enzyme immunoassay for hepatitis B virus core-related antigens and their correlation to virus load. J Clin Microbiol 2002;40:439-445.

13. Maasoumy B, Wiegand SB, Jaroszewicz J, et al. Hepatitis B corerelated antigen ( $\mathrm{HBcrAg}$ ) levels in the natural history of hepatitis B virus infection in a large European cohort predominantly infected with genotypes A and D. Clin Microbiol Infect 2015;21:606.

14. Seto WK, Wong DK, Fung J, et al. Linearized hepatitis B surface antigen and hepatitis B core-related antigen in the natural history of chronic hepatitis B. Clin Microbiol Infect 2014;20:1173-1180.

15. Seto WK, Tanaka Y, Wong DK, et al. Evidence of serologic activity in chronic hepatitis B after surface antigen (HBsAg) seroclearance documented by conventional HBsAg assay. Hepatol Int 2012;7:98105

16. Rokuhara A, Sun X, Tanaka E, et al. Hepatitis B virus core and core-related antigen quantitation in Chinese patients with chronic genotype B and C hepatitis B virus infection. J Gastroenterol Hepatol 2005;20:1726-1730.

17. Rokuhara A, Tanaka E, Matsumoto A, et al. Clinical evaluation of a new enzyme immunoassay for hepatitis B virus core-related antigen; a marker distinct from viral DNA for monitoring lamivudine treatment. J Viral Hepat 2003;10:324-330.

18. Wong DK, Tanaka Y, Lai CL, Mizokami M, Fung J, Yuen MF. Hepatitis B virus core-related antigens as markers for monitoring chronic hepatitis B infection. J Clin Microbiol 2007;45:3942-3947.

19. Wong DK, Seto WK, Cheung KS, et al. Hepatitis B virus corerelated antigen as a surrogate marker for covalently closed circular DNA. Liver Int 2017;37:995-1001.

20. Lam YF, Seto WK, Wong D, et al. Seven-year treatment outcome of entecavir in a real-world cohort: effects on clinical parameters, HBsAg and HBcrAg levels. Clin Transl Gastroenterol 2017;8:e125.

21. Suzuki F, Miyakoshi H, Kobayashi M, Kumada H. Correlation between serum hepatitis B virus core-related antigen and intrahepatic covalently closed circular DNA in chronic hepatitis B patients. J Med Virol 2009;81:27-33.

22. Lai CL, Wong D, Ip P, et al. Reduction of covalently closed circular DNA with long-term nucleos $(\mathrm{t})$ ide analogue treatment in chronic hepatitis B. J Hepatol 2017;66:275-281.

23. Ma H, Yang RF, Li XH, Jin Q, Wei L. HBcrAg identifies patients failing to achieve $\mathrm{HBeAg}$ seroconversion treated with pegylated 
interferon Alfa-2b. Chin Med J (Engl) 2016;129:2212-2219.

24. Yuen MF, Chan HLY, Liu KS, et al. Differential reductions in viral antigens expressed from CCCDNAVS integrated DNA in treatment naïve HBEAG positive and negative patients with chronic HBV after RNA interference therapy with ARC-520. J Hepatol 2016;64:S390-S391.

25. Tada T, Kumada T, Toyoda H, et al. HBcrAg predicts hepatocellular carcinoma development: an analysis using time-dependent receiver operating characteristics. J Hepatol 2016;65:48-56.

26. Cheung KS, Seto WK, Wong DK, Lai CL, Yuen MF. Relationship between HBsAg, HBcrAg and hepatocellular carcinoma in patients with undetectable HBV DNA under nucleos(t)ide therapy. J Viral Hepat 2017;24:654-661.

27. Seto WK, Wong DK, Chan TS, et al. Association of hepatitis B core-related antigen with hepatitis B virus reactivation in occult viral carriers undergoing high-risk immunosuppressive therapy. Am J Gastroenterol 2016;111:1788-1795.

28. Lee HA, Seo YS, Park SW, et al. Hepatitis B surface antigen titer is a good indicator of durable viral response after entecavir offtreatment for chronic hepatitis B. Clin Mol Hepatol 2016;22:382389.

29. Jung KS, Park JY, Chon YE, et al. Clinical outcomes and predictors for relapse after cessation of oral antiviral treatment in chronic hepatitis B patients. J Gastroenterol 2016;51:830-839.

30. Mak LY, Wong DK, Cheung KS, Seto WK, Lai CL, Yuen MF. Review article: hepatitis B core-related antigen (HBcrAg): an emerging marker for chronic hepatitis B virus infection. Aliment Pharmacol Ther 2018;47:43-54.

31. Gerelsaikhan T, Tavis JE, Bruss V. Hepatitis B virus nucleocapsid envelopment does not occur without genomic DNA synthesis. J Virol 1996;70:4269-4274.

32. Perlman D, Hu J. Duck hepatitis B virus virion secretion requires a double-stranded DNA genome. J Virol 2003;77:2287-2294.

33. Wang J, Shen T, Huang X, et al. Serum hepatitis B virus RNA is encapsidated pregenome RNA that may be associated with persistence of viral infection and rebound. J Hepatol 2016;65:700-710.

34. Rokuhara A, Matsumoto A, Tanaka E, et al. Hepatitis B virus RNA is measurable in serum and can be a new marker for monitoring lamivudine therapy. J Gastroenterol 2006;41:785-790.

35. Jansen L, Kootstra NA, van Dort KA, Takkenberg RB, Reesink HW, Zaaijer HL. Hepatitis B virus pregenomic RNA is present in virions in plasma and is associated with a response to pegylated interferon alfa-2a and nucleos(t)ide analogues. J Infect Dis 2016;213:224232.

36. Hatakeyama T, Noguchi C, Hiraga N, et al. Serum HBV RNA is a predictor of early emergence of the YMDD mutant in patients treated with lamivudine. Hepatology 2007;45:1179-1186.

37. Kurosaki M, Tsuchiya K, Nakanishi H, Itakura J, Izumi N. Serum HBV RNA as a possible marker of HBV replication in the liver during nucleot(s)ide analogue therapy. J Gastroenterol 2013;48:777778.

38. Su Q, Wang SF, Chang TE, et al. Circulating hepatitis B virus nucleic acids in chronic infection: representation of differently polyadenylated viral transcripts during progression to nonreplicative stages. Clin Cancer Res 2001;7:2005-2015.

39. van Bömmel F, Bartens A, Mysickova A, et al. Serum hepatitis B virus RNA levels as an early predictor of hepatitis B envelope antigen seroconversion during treatment with polymerase inhibitors. Hepatology 2015;61:66-76.

40. Huang YW, Takahashi S, Tsuge M, et al. On-treatment low serum HBV RNA level predicts initial virological response in chronic hepatitis B patients receiving nucleoside analogue therapy. Antivir Ther 2015;20:369-375.

41. Tsuge M, Murakami E, Imamura M, et al. Serum HBV RNA and HBeAg are useful markers for the safe discontinuation of nucleotide analogue treatments in chronic hepatitis B patients. J Gastroenterol 2013;48:1188-1204.

42. Butler EK, Gersch J, McNamara A, et al. HBV serum DNA and RNA levels in nucleos(t)ide analogue-treated or untreated patients during chronic and acute infection. Hepatology 2018;68:20162117.

43. Wang J, Yu Y, Li G, et al. Natural history of serum HBV-RNA in chronic HBV infection. J Viral Hepat 2018;25:1038-1047.

44. Gao Y, Li Y, Meng Q, et al. Serum hepatitis B virus DNA, RNA, and HBsAg: which correlated better with intrahepatic covalently closed circular DNA before and after nucleos(t)ide analogue treatment? J Clin Microbiol 2017;55:2972-2982.

45. Wang J, Du M, Huang H, et al. Reply to: "Serum HBV pgRNA as a clinical marker for cccDNA activity": consistent loss of serum HBV RNA might predict the "para-functional cure" of chronic hepatitis B. J Hepatol 2017;66:462-463.

46. Yuen MF, Kim DJ, Weilert F, et al. NVR3-778, a first-in-class HBV core inhibitor, alone and in combination with Peg-interferon (PegIFN), in treatment-naive HBeAg-positive patients: early reductions in HBV DNA and HBeAg. J Hepatol 2016;64:S210-S211.

47. Yuen MF, Coffin CS, Elkhashab SG, et al. SB 9200 an oral selective immunomodulator is safe and efficacious in treatment-naive, non-cirrhotic HBV patients: results from cohort 1 of the ACHIEVE trial. Hepatology 2017;66:22-23A.

48. Sato S, Li K, Kameyama T, et al. The RNA sensor RIG-I dually functions as an innate sensor and direct antiviral factor for hepatitis B virus. Immunity 2015;42:123-132. 